\title{
Sobre imaginário, mitos e arquétipos: exercício aplicado à narrativa audiovisual
}

\section{Fernanda Elouise Budag}

Doutoranda em Ciências da

Comunicação pela Escola de

Comunicação e Artes da Universidade de São Paulo. Docente da Faculdade Paulus de Tecnologia e Comunicação (FAPCOM).

Email: fernanda.budag@gmail.com
Resumo: Trazemos para o centro de nossa discussão o conceito de imaginário justamente pela relevância que acreditamos que ganha na contemporaneidade. Para estudar essa esfera, assumimos a metodologia de estudo do imaginário, a mitocrítica, desenvolvida por Durand (1985). Portanto, após introduzirmos a ordem imaginária e sua estruturação e explorarmos os preceitos da mitocrítica, apresentamos a série objeto de nosso estudo, Once upon a time, e propomos um exercício de aplicação da metodologia à série. Entendemos que a narrativa audiovisual promove imagens que interiorizamos, consistindo em fonte privilegiada para a construção de imaginários e, consequentemente, substrato pertinente para aplicação do método em questão.

Palavras-chave: Comunicação; Imagem; Imaginário.

Title: On imaginary, myths and archetypes: an applied exercise to audiovisual narrative

Abstract: We submit for discussion the concept of imaginary due to our belief of its relevance in contemporary times. In order to study this field, we used the imaginary study method developed by Durand (1985), myth criticism. Therefore, after introducing the imaginary order and its structure, and exploring the myth criticism dispositions, we present the subject of our study, the TV series Once upon a time, and propose a method application exercise. We realized that the audiovisual narrative promotes the internalization of images, becoming a privileged source for the construction of the imaginary and, as a result, an appropriate foundation for the application of the method at hand.

Keywords: Communication; Imagery; Imaginary. 


\section{Introduzindo a ordem imaginária}

No geral, buscamos recuperar a questão do imaginário e da metodologia no estudo proposto por Durand (1985) para evidenciar a importância que o imaginário adquire no mundo contemporâneo, principalmente com grandes produções midiáticas. Afinal, nós construímos as narrativas com imagens imagens e, automaticamente, imaginário.

Iniciamos, então, com a introdução da ordem imaginária e sua estruturação, continuando com a exploração dos preceitos da mitocrítica. Na sequência, após esse apanhado teórico, procuramos uma aproximação com a série ficcional televisiva objeto de nosso estudo, Once upon a time, propondo um exercício de aplicação da metodologia de estudo do imaginário defendida por Durand (1985) que exploramos aqui.

Primeiramente, de modo bastante simples, para em seguida entrar na complexidade do tema, assumimos que imagem é representação de um original, e que o imaginário decorre da imagem no sentido de que as imagens em circulação constroem compreensões de mundo.

${ }^{1}$ Conteúdo fornecido por Mayra Rodrigues Gomes em aula da disciplina "Ciências da linguagem: a ordem simbólica - fundamentos das reflexões sobre linguagem" sobre o Real, o Simbólico e o Imaginário, do Programa de Pós-graduação em Ciências da Comunicação da Escola de Comunicações e Artes (ECA) Universidade de São Paulo (USP), em 09 de maio de 2013.

\footnotetext{
${ }^{2}$ Conteúdo fornecido por Silvio Anaz em aula da disciplina "Ciências da linguagem:
}

Para tratar de questões da ordem imaginária, Gomes (informação verbal) ${ }^{1}$ trabalha com notações que, em sua origem, vêm do estruturalismo e que foram tomadas e codificadas pelo psicanalista Jacques Lacan, propondo certa compreensão de mundo do ponto de vista da linguagem. Nessa perspectiva, nos constituímos como sujeitos em uma realidade compreendida como a articulação entre as esferas do Real, do Simbólico e do Imaginário. Nesse contexto, o Real (com " $r$ " maiúsculo) é uma massa amorfa, enquanto o Simbólico seria a esfera que coloca as coisas desordenadas dessa massa amorfa em nosso entendimento, organizando-as. A ordem simbólica compreende então uma espécie de malha jogada em cima do pano de fundo que é o Real (que, a rigor, existe para dar sustentação à ordem simbólica). A ordem simbólica vai, assim, "amarrando nós", ou seja, produzindo sentidos. E aí já estamos na ordem do Imaginário; é essa a realidade na qual nos locomovemos.

Nessa linha de raciocínio, a mídia em geral e as narrativas audiovisuais em particular - apenas para focar no produto objeto de nosso estudo - promovem imagens que interiorizamos, correspondendo a fontes privilegiadas para a construção de imaginários.

Compreendemos, portanto, o imaginário a partir das concepções de Durand (2000), o qual, em sua obra, estudando a imaginação simbólica, chega a uma teoria do imaginário. O sociólogo francês explica o imaginário por meio do que chama de "trajeto antropológico" (DURAND, 2000): a esfera subjetiva e a esfera social do sujeito - Durand $(1985,2000,2004)$ sempre trabalha a questão do imaginário nesses dois aspectos, o psicológico e o sociológico - estabelecem relações mútuas por meio de "estruturas do imaginário", como mitos, imagens, símbolos e arquétipos, as quais seriam todas atitudes imaginativas dos sujeitos. Acreditamos que as narrativas audiovisuais ocupam uma posição privilegiada como reveladoras de atitudes imaginativas - justificando a relação entre nosso objeto de estudo e as questões do imaginário que colocamos aqui.

Em outros termos, o imaginário é um enquadramento a partir do qual entendemos as coisas do mundo. Ou, mais próximo à terminologia de Durand - a partir daqui dialogamos com Durand (1985, 2004) e Anaz (informação verbal²) -, imaginário enquanto conjunto de atitudes imaginativas que o homem produz desde sempre. Assim, o imaginário teria emergido em virtude da percepção/ consciência humana sobre a finitude e a passagem do tempo, que gera angústia e exige o desenvolvimento de mecanismos mentais para lidar com elas. Dessa forma, Durand (2004) entende que o imaginário é esse mecanismo principal - a 
vida seria impossível sem esses mecanismos - que tem a função, portanto, de dar um equilíbrio biopsicossocial ao ser humano.

\section{Entendendo a estruturação imaginária}

Os arquétipos e os mitos são elementos fundamentais para entender o que é o imaginário. Durand (1985) recupera a ideia de arquétipo de Jung como imagem primordial e avança apresentando o já citado percurso antropológico no qual o arquétipo se insere, ou seja, na base de toda produção humana. Arquétipo como uma das primeiras imagens que vêm à mente do ser humano em seu desenvolvimento, ou ainda como matriz primordial que é preenchida cultural e historicamente por imagens e símbolos; arquétipos enquanto núcleos organizadores das produções culturais dos sujeitos.

O mito, por sua vez, seria a primeira racionalização do arquétipo, sob a forma de relato, de narrativa; um discurso sobre elementos do mundo social e/ou do mundo cultural. O mito seria, então, uma narrativa desenvolvida em cima de um arquétipo.

Ferry (2009) situa o mito como narração que tenta responder de forma leiga à questão da vida boa - questão primordial da filosofia - sob a forma de literatura, de poesia ou de epopeia; essas narrações trazem lições de sabedoria com profundidade filosófica. Segundo ele, as mitologias, especialmente a grega, em que o filósofo francês se foca, são a primeira tentativa dos gregos de entender o mundo, de explicar o mundo do ponto de vista filosófico, religioso e científico.

Já a antropologia moderna define o mito como relato (discurso mítico) que coloca em cena personagens, cenários e situações geralmente não naturais, divinos, utópicos, nos quais está investida uma crença. Assim, o discurso mítico acaba sendo aplicado às questões metafísicas, que escapam à ciência. Nesse sentido, a mitologia e os mitos procuram explicar de onde viemos, o que acontece após nossa morte e por que existe o mundo. Questões que estão além do que a ciência consegue explicar e para as quais o discurso mítico tenta dar uma satisfação.

Dando continuidade, e conforme já pontuamos, o mito é uma racionalização do arquétipo. Ou seja, o arsenal simbólico que forma o mito é constituído pelas grandes imagens arquetípicas - aliás, todo discurso mítico trabalha questões arquetípicas, e mitos fundadores trazem arquétipos fundadores. Por conseguinte, Durand (1985) defende que esses mitos fundadores estão permanentemente circulando na sociedade, em maior ou menor evidência. Fazendo uma comparação com os níveis psicológicos, o filósofo sugere que os mitos circulam em três níveis na sociedade. O primeiro nível, mais basal, que ele chama de "inconsciente antropológico", é o nível fundador no qual estão os arquétipos (afinal, como já pontuamos, os mitos trazem essas grandes imagens arquetípicas e trabalham nelas). Já o segundo nível, "ego societal", é onde está a ideologia e, por sua vez, o terceiro nível, "superego societal", é o que temos contato no dia a dia, na pedagogia, nas instituições, nas mídias - nas quais os mitos se manifestam de forma mais clara.

Nesses termos, significa que temos mitos dominando o pensamento em cada fase da humanidade. Esses mitos circulando (dominando, emergindo ou decaindo) é a grande ideia de Durand (1985) quando fala sobre como os mitos atravessam a sociedade. É difícil apreender isso tão de imediato, é necessário um aprofundamento, pois os mitos estão sob várias camadas de histórias e mudanças sociais que os tornam latentes, escondidos sob várias camadas de cultura. É necessário empreender uma análise de "mitemas" - termo que Durand (1985) empresta de Lévi-Strauss (1975, p. 243), antropólogo francês -, entendidos como elementos, índices fundamentais que mostram a presença de um mito em determinada sociedade ou em certa narrativa. É, portanto, analisando os mitemas 
e como eles se articulam que identificamos os mitos dominantes ou em ascensão em uma determinada sociedade.

Retomando, e levando em consideração o imaginário enquanto mecanismo mental para lidarmos com a morte, o imaginário desenvolve como recurso a tentativa de derrotar ou suavizar a morte - Durand (1985) divide isso em dois regimes de imagens: o diurno e o noturno. Basicamente, o diurno representaria a vontade de derrotar a morte, e o noturno a vontade de suavizar a morte, aceitando-a. Dentro desses regimes há estruturações mentais que vão gerar os arquétipos e os mitos. No regime diurno há uma estruturação heroica em que prevalece o tema do combate, enquanto no noturno temos duas estruturas: a mística e a sintética. Na mística prevalece uma atmosfera de repouso, e na sintética há tanto o combate quanto o repouso, agrupando elementos da estruturação heroica e da mística (seria o regime "crepuscular", intermediário entre o diurno e o noturno). Portanto, conforme as concepções de Durand (1985), teríamos imagens que pertenceriam mais a um regime diurno e imagens que pertenceriam mais a um regime noturno.

O que vale ressaltar é que o significado de tudo isso é que enxergamos o mundo por meio de mitos, cada sujeito a seu modo. Cada um de nós vê o mundo de acordo com um universo mítico, que pode mudar em diferentes momentos de nossas vidas. Alguns sujeitos revelam que conservam um microuniverso mítico de estruturação heroica - no qual o herói pode triunfar ou fracassar -, enquanto outros podem revelar um microuniverso mítico de estruturação mística, e outros, ainda, sintética. Isso corresponde a uma forma particular de entender o mundo, a sociedade em que vivemos e os produtos culturais. Em outras palavras, nós operamos naturalmente a vida com esses regimes e estruturações imaginárias, que também dizem respeito, obviamente, a como produzimos determinadas narrativas. Geralmente as narrativas têm características de ambos os regimes, mas algum deles pode predominar em determinada narrativa.

\section{Compreendendo a mitocrítica}

Basicamente, essa é a ideia de Duran: conseguimos olhar para a sociedade e para a produção cultural por meio de um olhar mítico, que tenta identificar quais são os mitos que estão ditando a forma de pensar e agir de uma sociedade ou manifestação cultural. Para tanto, Durand (1985) desenvolve uma metodologia para analisar a sociedade e os produtos culturais, baseada principalmente na questão do imaginário, nos mitos e nos arquétipos. Mitodologia é o nome genérico que ele dá a essa metodologia, que abarca duas formas de análise: a mitocrítica e a mitanálise. No final dos anos 1960, o autor desenvolve sua primeira mitodologia, chamada mitanálise, para ser aplicada à análise de um grande período histórico ou social, sendo definida como um método científico de análise dos mitos que busca sentidos psicológicos e sociológicos. A mitanálise tenta compreender os grandes mitos - mitos patentes (evidentes) e latentes (escondidos) - que orientam os momentos históricos, grupos e relações sociais. Durand (1985) quer dizer com isso, conforme já pontuamos, que durante toda nossa história sempre houve mitos determinando a forma como nós conduzimos a vida.

Foi a partir da mitanálise que o autor desenvolveu o conceito de mitocrítica, que nos interessa mais por ser uma proposta metodológica que cabe para a análise de um produto midiático. $\mathrm{O}$ avanço da mitocrítica está em ser uma crítica que não se concentra somente na esfera da produção (como seria a semiologia) e na esfera da recepção (que seria a psicologia), e sim no encontro delas, no encontro entre o universo mítico do leitor e o universo mítico do autor (quando falamos do autor, diz respeito aos microuniversos míticos ligados ao regime diurno e noturno de uma obra, aspecto já antes mencionado). A mitocrítica foca no imaginário compartilhado que emerge desde o processo criativo até a recepção. Assim, a mitocrítica corresponde a uma metodologia aplicada aos produtos culturais, 
${ }^{3}$ Conteúdo fornecido por Silvio Anaz em aula da disciplina "Ciências da linguagem: fundamentos das práticas midiáticas I" sobre Mitocrítica aplicada a narrativas midiáticas, do curso de graduação em Jornalismo da ECA-USP, em 25 de maio de 2015.

\footnotetext{
${ }^{4}$ CANAL SONY BRASIL. Once upon a time primeira temporada. Disponível em: $<$ http:// www.youtube.com/watch?v=yVLQvuSOKzc>. Acesso em: 15 out. 2012.
}

como as narrativas midiáticas. A mitocrítica busca analisar o imaginário saído de um produto cultural que traz esses microuniversos míticos tanto do autor como do receptor. E nesse processo a mitocrítica se baseia, sobretudo, no conceito de mito.

Segundo Anaz, para empreender essa mitocrítica em uma determinada produção cultural, como uma série ficcional televisiva, são necessários basicamente três passos (informação verbal ${ }^{3}$ ). O primeiro seria levantar temas redundantes nesse produto cultural; temas e motivos que mais aparecem, assim como situações, personagens e combinações de situações e personagens (elementos simbólicos) que são mais recorrentes na obra. O segundo passo seria fazer uma convergência desses elementos simbólicos em função de seus sentidos e funções na narrativa. A convergência desses elementos leva à identificação de um mitema muito forte, que vai conduzir para um determinado mito (geralmente grego). $O$ terceiro passo seria identificar no universo da produção cultural as correlações com os mitos fundadores de uma determinada época e cultura. Essa última etapa (relacionar as funções e sentidos em uma narrativa com os mitos fundadores) é a parte mais difícil, visto que os mitos estão latentes, escondidos embaixo de várias camadas culturais.

\section{Conhecendo Once upon a time}

Conforme já situado no resumo, o produto midiático que compõe nosso objeto de estudo consiste em uma série ficcional televisiva norte-americana chamada Once upon a time, que estreou na rede de televisão ABC em outubro de 2011 e está atualmente em sua quinta temporada. Criada por Edward Kitsis e Adam Horowitz, escritores de Lost, série de grande sucesso, Once upon a time é transmitida no Brasil, na TV por assinatura, desde abril de 2012 pelo Canal Sony; já na TV aberta, quem transmite, desde fevereiro de 2014, é a Rede Record. Nosso recorte para análise nesse espaço é somente a primeira temporada ${ }^{4}$ da série. Portanto, tudo o que trazemos aqui diz respeito somente à narrativa transcorrida nos 22 episódios (de 43 minutos cada) dessa temporada inicial.

A narrativa de Once upon a time é construída a partir do uso de inúmeras referências de antigos contos de fada, ao mesmo tempo em que opera uma transposição desse repertório encantado para o contexto do mundo real e atual. Seu título tem a tradução literal "Era uma vez", a clássica frase inicial de contos de fada, justamente porque adota como universo ficcional o Reino Encantado, integrando personagens e elementos icônicos: Grilo Falante, Gepeto, Pinóquio, Bela, Chapeleiro Maluco, Caçador, Chapeuzinho Vermelho e a Vovozinha, maçã envenenada, entre tantos outros. Ou melhor, a narrativa se inicia no Reino Encantado, com o casamento de Branca de Neve e Príncipe Encantado, mas uma maldição da Rainha Má transporta os personagens para um lugar no qual suas vidas e lembranças seriam roubadas, e onde não haveria mais finais felizes: o Mundo Real. Assim sendo, estão todos presos em uma cidade litorânea chamada Storybrooke - cidade fictícia do Maine, estado localizado no extremo nordeste dos EUA -, e aí a estória se desenrola pelo intercalar dos dois mundos e a batalha contra a maldição.

Em quase todos os episódios há dois enredos paralelos que se alternam na tela: um que se passa em Storybrooke (o Mundo Real da série), geralmente no tempo presente, e outro que se passa, em flashback, no Reino Encantado, normalmente com foco central em um momento passado da vida de um personagem antes da maldição. Detalhando um pouco mais, descrevemos brevemente a sinopse da primeira temporada - nosso foco neste estudo. Ela inicia justamente como já apontamos, com o casamento de Branca de Neve e Príncipe Encantado e a interrupção da cerimônia pela Rainha Má anunciando a maldição. Com a concretização do feitiço, todos os personagens são transportados para Storybrooke, perdendo suas memórias e identidades de personagens de contos 
de fada. A exceção é Emma, filha recém-nascida de Branca de Neve e Príncipe Encantado, que foi colocada em um armário mágico que a conduziu ao Mundo Real antes da maldição, protegendo-a. Emma, portanto, é a única que pode quebrar o encanto e restaurar lembranças e identidades de todos e ainda libertálos, pois - eles não percebem -estão presos na cidade; sempre que algum deles tenta sair, algo acontece para impedi-los. Sem saber de nada disso, Emma mora em Boston e, no dia de seu aniversário de 28 anos, recebe a visita de Henry Mills, seu filho biológico que ela deu para adoção logo após o nascimento. O menino, de 10 anos, desconfia de toda essa maldição - lançada pela Rainha Má, que é Regina Mills, mãe adotiva de Henry no Mundo Real -, e possui um livro de histórias (intitulado Once upon a time) que acredita conter a chave para quebrá-la; por isso apareceu para pedir a ajuda de Emma, pois crê, conforme seu livro, que ela seja a filha de Branca de Neve destinada a dar um fim nesse feitiço. Emma vai até Storybrooke para devolver Henry e fica intrigada com a relação de Henry e Regina, e acaba permanecendo na cidade. O menino então passa a temporada tentando convencer Emma sobre essa história e ela acaba tendo que enfrentar muitos inimigos e desafios até finalmente quebrar a maldição no último episódio da temporada.

\section{Aplicando a mitocrítica à Once upon a time}

Quando Durand (1985) propõe a mitanálise e a mitocrítica, sugere que elas sejam aplicadas em longos períodos históricos ou amplo conjunto de obras. Ele não aplicou a mitocrítica para uma obra isolada, que segundo ele não teria elementos suficientes para identificar os mitos, ou seja, seria uma análise muito frágil. De qualquer forma, propomos fazer um exercício de aplicação da mitocrítica à Once upon a time, uma vez que a série já está em sua quinta temporada, correspondendo a uma produção substancial da narrativa. Trata-se somente de um exercício por dois motivos: fizemos em cima de um recorte de somente três personagens que nos parecem importantes para a primeira temporada da série; e pelo fato de que não pretendemos alcançar o nível mais profundo da análise, identificando o mito que fundamenta a narrativa; executamos somente os dois passos iniciais, procurando extrair os temas recorrentes em torno desses personagens e, consequentemente, buscando enxergar os arquétipos aí trabalhados e os regimes de imagens em que se situam. Os personagens que selecionamos para essa análise da narrativa de Once upon a time via mitocrítica são: Emma Swan, Mary Margaret Blanchard e Sr. Gold - todos do Mundo Real da série.

Emma Swan é claramente a personagem principal da trama passada no Mundo Real da série, sobretudo por ter o poder de quebrar a maldição. É uma jovem que foi abandonada pelos pais quando criança, e que aos 18 anos engravida de Henry e o dá para adoção. Ou seja, sua vida não foi fácil. Antes de ir para Storybrooke, morou em Boston. Somado ao fato de não ter familiares próximos, ainda vive em uma grande cidade (quase seis milhões de habitantes) e, visivelmente, sente-se sozinha - o que deixa transparecer em seu aniversário de 28 anos, no primeiro capítulo. Mas é também, perceptivelmente, uma mulher extremamente forte - talvez justamente pelas dificuldades enfrentadas em sua trajetória. Trabalha como agente de fiança ("caçadora de recompensas") em Boston, e depois em Storybrooke assume a posição de xerife da cidade - atividades profissionais que exigem pessoas firmes. Ou seja, Emma foge do estereótipo de princesa delicada. Pelo contrário, é corajosa e determinada, como se vê em sua busca obsessiva pela verdade, pela justiça e pela quebra da maldição. Identificamos que os temas trabalhados que se referem à personagem Emma Swan giram em torno de: força, determinação, independência e justiça. Temas em sua maioria que situam a personagem em uma lógica de combate, posicionando-a no regime diurno das imagens; características essas que também remetem ao arquétipo do herói que fundamenta a personagem: "um Herói é alguém que está disposto a sacrificar suas próprias necessidades em benefício dos outros" (VOGLER, 2009, p. 75), aos 
moldes da aventura que Emma se propõe a enfrentar na tentativa de ajudar Henry e os demais habitantes da cidade.

Dando continuidade, Mary Margaret Blanchard é uma professora da escola primária de Storybrooke. Enxergamos seu protagonismo em virtude de ser, no Mundo Real, a contraparte de Branca de Neve do Reino Encantado, a qual seria, portanto, "mãe" de Emma. O amor é temática recorrente em sua vida, pois vive a angústia de amar David, seu par no Reino Encantado, mas um homem casado no Mundo Real. Ela é voluntária no hospital local no início da série e é sempre muito bondosa, delicada e carinhosa. Protetora, oferece estadia a Emma e passa a apoiála e colaborar em suas várias empreitadas contra Regina - prefeita da cidade. Entre os temas mais recorrentes trabalhados em torno da personagem Mary Margaret, identificamos: amor, esperança e bondade. Nesse sentido, percebemos uma atmosfera de repouso, que localiza a personagem automaticamente no regime noturno místico. O arquétipo por trás da personagem aproxima-se do mentor, "figura positiva que ajuda ou treina o herói [...]", que "se expressa em todos aqueles personagens que ensinam e protegem os heróis e lhes dão certos dons" (VOGLER, 2009, p. 89). Enxergamos o mentor na personagem especialmente por Mary Margaret ser a mãe que Emma não teve. Além de abrigá-la e ajudá-la, em certo sentido Mary Margaret transmite ensinamentos a Emma, sobretudo em termos de relacionamento e confiança - esferas em que Emma é bastante carente.

Por fim, Sr. Gold, personagem do Mundo Real de Once upon a time, em nossa visão, é figura central na narrativa porque interliga direta ou indiretamente todos - ou praticamente todos - os demais personagens. No passado, no Mundo Encantado, seu personagem, Rumplestiltskin, mantém ao menos uma história com cada um dos demais personagens principais. No Mundo Real, Sr. Gold é introduzido como o "dono" de Storybrooke, proprietário de muitos imóveis na cidade, além de dono da Casa de Penhores e Antiguidades. Tanto Sr. Gold quanto sua contraparte, Rumplestiltskin, são extremamente poderosos (em virtude de magia no Reino Encantado e em função de posição social no Mundo Real). Desse modo, Sr. Gold está sempre sendo procurado (ou procurando) por demais personagens para selar acordos que os ajudam em um primeiro momento, mas pelos quais terão um preço a pagar no futuro. Dessa forma, o personagem parece sempre migrar entre o bem e o mal. Nunca sabemos de imediato seu real interesse por trás de cada uma de suas ações e alianças. Entre os temas que norteiam Sr. Gold, identificamos especialmente magia/poder e trocas de favores representados pelos tantos acordos interesseiros que firma. Seu perfil nos leva a localizá-lo no regime diurno sintético das imagens, por seguir uma lógica cíclica que se desloca entre os estados de combate e de repouso. Nessa linha, o personagem está embasado no arquétipo do camaleão (VOGLER, 2009, p. 115116), que preserva uma natureza mutante e instável, difícil de ser capturada e que muitas vezes confunde o herói.

No quadro a seguir, resumimos as linhas gerais da análise inspirada na mitocrítica que acabamos de traçar desses três personagens:

\begin{tabular}{|c|c|c|c|}
\hline Personagem & Temas & Regime de imagem & Arquétipo \\
\hline Emma Swan & $\begin{array}{c}- \text { Força } \\
- \text { Determinação } \\
- \text { Independência } \\
- \text { Justiça }\end{array}$ & Regime diurno & Herói \\
\hline $\begin{array}{c}\text { Mary Margaret } \\
\text { Blanchard }\end{array}$ & $\begin{array}{c}- \text { Amor } \\
- \text { Esperança } \\
- \text { Bondade }\end{array}$ & Regime noturno místico & Mentor \\
\hline Sr. Gold & $\begin{array}{c}\text { - Magia/poder } \\
- \text { Acordos }\end{array}$ & Regime diurno sintético & Camaleão \\
\hline
\end{tabular}

Quadro 1: Exercício de aplicação da mitocrítica à Once upon a time Fonte: Elaboração da autora, 2015. 
Traçando considerações finais

De toda nossa explanação, guardamos, sobretudo, que uma narrativa - como Once upon a time, produto objeto de nossa investigação - é fonte e produto do imaginário. Uma narrativa midiática alimenta o imaginário na mesma medida em que é alimentada por ele. A sociedade/cultura e o imaginário se retroalimentam. Uma vez que o pensamento em vigor de certa época em uma determinada sociedade tem sua base no mito - mesma matriz da narrativa -, estudar uma narrativa é estudar uma sociedade. Desconstruindo uma narrativa, chegamos ao princípio do pensamento de uma sociedade.

Podemos, assim, considerar que a partir da desconstrução da narrativa de Once upon a time na base do pensamento de nossa sociedade - substrato da série -, temos a permanência da dualidade entre a sensibilidade que acompanha o amor e a rigidez que exige a justiça; em meio a esses dois extremos, existem as mutações e a instabilidade. O pensamento contemporâneo está em eterna metamorfose, característica de tempos líquidos, como diria Bauman (2001).

Produto desses tempos contemporâneos e fonte para a construção de imaginários, ficam alguns questionamentos para posteriores discussões: por que uma série atual está resgatando, hoje, esses contos clássicos? E porque lhes dão os contornos que Ihes dão? Afinal, o que tudo isso diz de nossos dias? Por que essa história foi criada agora? Que reflexões podemos tecer de nosso cotidiano do qual essa narrativa emerge em primeira instância, visto que a narrativa não é descolada de seu referente no mundo social concreto? Tecemos nossas considerações sobre a realidade construída numa narrativa audiovisual, mas merece reflexões a realidade a partir da qual essa narrativa é construída.

\section{Referências Bibliográficas}

BAUMAN, Z. Modernidade líquida. São Paulo: Zahar, 2001.

DURAND, G. Sobre a exploração do imaginário, seu vocabulário, métodos e aplicações transdisciplinares: mito, análise e mitocrítica. Revista da Faculdade de Educação, v. 11, n. 1-2, p. 244-256, 1985.

. A imaginação simbólica. Lisboa: Edições 70, 2000.

. O retorno do mito: introdução à mitodologia. Mitos e sociedades. FAMECOS, v. 1, n. 23, p. 7-22, 2004.

. As estruturas antropológicas do imaginário - introdução à arquetipologia geral. 4. ed. São Paulo: Martins Fontes, 2012.

FERRY, L. A sabedoria dos mitos gregos - aprender a viver II. Rio de Janeiro: Objetiva, 2009.

LÉVI-STRAUSS, C. Antropologia estrutural. Rio de Janeiro: Tempo Brasileiro, 1975.

ONCE UPON A TIME. Direção: Edward Kitsis e Adam Horowitz. $1^{\text {a }}$ temporada. Estados Unidos: ABC Studios, 2012. 5 DVDs (947 min.). son., dolby digital 5.1, color.

VOGLER, C. A jornada do escritor: estruturas míticas para escritores. 2. ed. Rio de Janeiro: Nova Fronteira; Sinergia; Ediouro, 2009. 